\title{
Intersections of gender and age in access- ing River Basin Resources in Tanzania: a comparative analysis of fishing and agro-pastoralist communities in rural areas of Tanzania
}

\author{
Christina M. SHITIMA $(1,2)$
}

(I) Department of Economics, Mzumbe University, Morogoro Tanzania

(2) Institute of Development Policy, University of Antwerp, Belgium

\begin{abstract}
This paper applies intersectionality theories to investigate how informal social relations factors in terms of age and gender interact to affect people's access to river basin resources (RBR) in Tanzania. Access to RBR is defined as practical rights to use RBR and benefits that are accrued from the use of RBR. Data were collected from a survey conducted among households living along the Kilombero River in Tanzania. Three villages that differ in cultural backgrounds i.e. a fishing community, an agro-pastoralist community and a village with people from multi-cultural groups were included in the survey. A multivariate probit model is used to determine access in terms of practical rights to use RBR, and a generalized ordered logit model is used to determine access in terms of benefits from the use of RBR. Findings show that both practical rights to use RBR and benefits from the use of resources are highly gendered, though their impact differs according to age groups and cultural groups. One common feature in all cultural groups is that the norms that deny women rights to use RBR result in a gendered distribution of labour, especially when access to RBR leads to income-generating activities. The findings also highlight that women are less likely to benefit from the use of resources. Within a single cultural group, a fishing community, the study found that benefits from the use of RBR vary according to age. In line with intersectionality theories, we conclude that, both men and women are heterogeneous groups in societies. While it is generally perceived that women in rural areas are the victims of norms that deny their development, this is not the case for all women. Findings also reveal the importance of distinguishing between practical rights to use resources and benefits derived from their use.
\end{abstract}

Key words: River Basins Resources, access to river basin resources, practical rights to use resources, ability to benefit from resources, gender, intersectionality 


\section{Introduction}

The study applies intersectionality theories in its examination of access to RBR in rural areas of Tanzania. The paper argues that livelihoods of some people who live in the villages along river basins in Tanzania might be affected by differences in access to river basins resources (RBR) ${ }^{\mathrm{I}}$. These differences in access to RBR are the result of cultural norms and beliefs that create diverse social relations in society. These include differences in wealth, knowledge, age, and gender, all of which create differences in power relations among actors. Agarwal (1997) argues that, in rural areas of developing countries, livelihood resources are not equally accessible for men and women. This is due to power differences created by socially constructed practices in terms of gender. For instance, in Tanzania, while there are strong legal provisions that give rights to and protect women's ownership of land, most customary norms give rights to women to use land through their spouses or male family members and deny them rights to own or to transfer land (Leavens \& Anderson, 20II: 2). Even at a household level, females do not inherit resources from their fathers, as most cultures favour men's inheritance of resources (Leavens \& Anderson, 20II $)^{2}$. While diversity in social relations is considered to create differences in power relations among actors, the literature also shows that differences in power relations may also cause diversity in social relations between members of society. Some actors may use their power to benefit more from resources than others (Cleaver, 200I; Cleaver \& Toner, 2006; Mehta, Leach, \& Scoones, 200I). For instance, people who possess certain skills and/ or other forms of resources may have substantial capacities to negotiate and/ or manoeuvre and shape the use of shared RBR to their advantage and thus accrue more benefits. Furthermore, some groups of actors with power may deny other groups the rights to access important resources. De Haan and Zoomers (2005: 33) have referred to such denial as social exclusion, i.e. "a process in which groups try to monopolize specific opportunities to their own advantages".

In line with Leach, Mearns, \& Scoones (I999) and Ribot \& Peluso (2003), this paper defines individual access to RBR in terms of practical rights to use household owned RBR to pursue different livelihood activities and the ability to benefit from the goods that were produced from the use of RBR. In most societies, formal and informal rules operate together to determine the rights to use natural resources. While the state provides formal (legal) rights on the use of RBR through rules and regulations, other customary (informal) norms operate alongside formal rules to govern the uses of resources. This situation is referred to in the literature as legal pluralism (Meinzen-Dick, 20I4; Meinzen Dick and Pradhan 2002), whereby different types of arrangements/ rules are used in allowing access to natural resources. For example, Cleaver (200I) shows that at the Usangu

I River basins in Tanzania provide important natural resources which are used for different livelihood activities. These resources include water for irrigation, fisheries, areas for livestock, trees for the construction of houses and sources of energy, recreational areas etc.

2 In Tanzania, the formal laws that govern inheritance give equal rights to all children regardless of their gender, unless it is stated otherwise in the will of a parent. However, most of the inheritance trials are conducted at the household level by using the traditional rules and customs i.e. the trials are not taken to formal system of laws. 
River in Tanzania, conflicts over use of irrigated water are referred to traditional elders instead of being reported to formal systems of laws, which people found to be unnecessary. Thus, even with the existence of formal rules, people not only use the rules that are familiar but also those that seem to be more advantageous. Showing the role of both formal and informal rules in shaping outcomes of access to resources, Leach et al. (I999: 237) have referred to these rules as "not as the rules themselves, but as regularized patterns of behaviour that emerge from underlying structures or sets of 'rules in use'... 'rules' are constantly made and remade through people's practices. In this paper, we argue that a household's legal possession of rights to the use of RBR or physical ownership is not a sufficient condition for an individual household member to have practical rights to use that resource ${ }^{3}$. Customary norms interact with modern ways of livings (see also Hall, Cleaver, Franks, \& Maganga, 20I4) to determine the ways resources are used by different household members. Thus, the term rights to use RBR is used in this paper to mean the practical rights that an individual has on the use of household owned RBR.

The benefits that a person has from the use of livelihood resources is regarded in this study as the freedom that a person has to make decisions about the uses of goods she/he has produced (Leach et al., I999; Sen, I999). While the right to use resources is an important condition for a person to be able to produce goods, studies show that the right to use resources does not guarantee the accrual of benefits that result from the use of RBR (Ribot \& Peluso, 2003). Thus, even if a person is able to use RBR to produce goods, the ability to use the yields to meet personal needs is also an important condition for him/ her to benefit from the use of RBR. Other literature has shown that the freedom to decide whether to use produced goods and how to use them also defines the ability to benefit as people have different life-goals (Leach et al., I999; Sen, I999). Leach et al. (I999) show that informal relation factors such as differences in gender, age and other forms of socially constructed practices moderate the whole process of gaining benefits. For instance, some resources may not be utilized for the improvement of livelihoods due to religious beliefs, norms and/ or traditions that prohibit certain groups of people from using those resources. In a polygamous marriage, wives may not be able to benefit from the goods produced by the household, if only the husband makes the selling/consumption decisions.

From the above arguments, this paper raises the following important questions regarding access to RBR in Tanzania: How do men and women access RBR that are owned by households for the enhancement of their livelihoods? The following three hypotheses are then tested: (i) gender differences derived from cultural norms affect individual rights

Studies of the unitary approaches and common preference models (Becker, I965; Haddad, Hoddinott, \& Alderman, I997; Singh, Squire, \& Strauss, I986) stipulate that production and consumption decisions in rural areas are made at the household level rather than by an individual person. In these models, the household is seen as well-being maximizing unit, whereby all households members are assumed to have the same preference for production and consumption of goods. Drawing upon the studies of unitary approaches, this study assumes that in rural areas of Tanzania, RBR that are used for production are owned at household level and the production decision is made at household level. All household's members use the same RBR to produce goods that are consumed by all household's members. 
to use RBR, (ii) gender differences derived from cultural norms affect the ability to benefit from the use of resources, and (iii) there is a link between the rights to use RBR and the ability to benefit from the use of resources (both for men and women). In addition, by using intersectionality approaches (see for example Crenshaw, 1989), the paper argues that some people' access to RBR may be more affected than others, as they belong to different social categories of marginalization. In this study, we more specifically use intersectionality theories to study how informal social relations in terms of age and gender intersect to affect people's livelihoods in terms of the access they have to important RBR. Furthermore, the study also tries to determine whether the impact of the intersection of these variables differs between people of different cultural norms.

The findings of this study are important in terms of understanding whether the livelihoods of men and women are enhanced or hindered by norms that discriminate not only some people's rights to use RBR but also their ability to benefit from the use of those resources. Importantly, following Jones et al. (2010:7) we insist that these socially constructed practices "are not inherently good or bad". However, when they create "inequality, discrimination and exclusion, they become detrimental to development". Institutions of cultural norms and practices can be detrimental to development, for example, when they deny a certain group of people rights to access certain productive activities that are found within a particular society, and/or if they limit some people's abilities to benefit from the available societal resources to improve their livelihood outcomes. Thus, the study is also important with respect to recommending policies that promote development initiatives that take into account the different opportunities and challenges faced by (different groups of) men and women in terms of the improvement of their livelihoods. In addition, the study extends the literature on the intersectionality approaches by applying the theory to study rural people's behaviour in relation to access to resources. Traditionally, intersectionality studies have been focussed on the interactions of social categories that are related to race, gender, class, in the main comparing people of different cultural backgrounds. In this paper, first people with similar cultural norm are studied. Subsequently, the scope is broadened to a comparison between different cultural groups.

The paper is organized as follows: the following section presents the literature on intersectionality theories, followed by section three, which gives a brief description of the study area. Methodology is presented in section four, followed by results and discussion of findings in sections five and six, respectively. Section seven gives the conclusion and policy implications of the study's findings.

\section{Intersectionality theories}

Intersectionality is an approach in research that is used to study how different social categories intersect to affect people's lives in different ways, compared to the impact of a single social category. Having its roots in legal studies, intersectionality theory was first introduced by Kimberlé Crenshaw (I989) who studied the marginalizations experienced by African-American women in America. She showed that African-American women face double marginalization compared to other groups of people (white women, black men 
etc.), because they belong to more than one group of social marginalization. Extending the intersectionality theory, Hill Collins (2000) explained three dimensions that put a black woman in America in an oppressive situation. She pointed out that black women were economically oppressed because of the history of being slaves for white men; politically oppressed, as they were not allowed to vote and to hold public office; and ideologically oppressed because of the stereotypes that perceived them as prostitutes and people of low class in society. While different people fall into different categories of discrimination, intersectionality theorists challenged the anti-discrimination laws for assuming discrimination affects all people equally. For example, they contest the laws that assume sex discrimination affects all women equally or that race discrimination affects all people of colour equally (Best et al., 20II). Intersectionality theorists argue further that people are not homogeneous in terms of oppression they experience i.e. different people experience different magnitudes of oppression. There are other social arrangements that intersect with constructs such as gender and/ or race to bring more oppression to some groups of people. For example, if employers practice sexual discrimination against women when recruiting new employees for positions that are traditionally perceived to be male jobs, that kind of discrimination is one dimensional as it affects all women. However, if an employer refuses to hire disabled women in certain positions, these women are discriminated against not only because of their gender, but also because of their disability. Thus, disabled women may experience a double impact of social marginalization associated with socially constructed practices, because they are caught in an intersect of different social identities. The intersectionality theorists argue for the need to study how different social categories intersect to affect people's lives in different ways instead of treating them as one-dimensional categories (Best, Edelman, Krieger, \& Eliason, 20II).

In rural areas of developing countries, informal social relations embedded in norms and culture strongly determine the behaviour that is expected from women and men, and from old and young people, etc. For example, women are socialized to be the care givers of the families and men are expected to engage in activities that generate income and accumulate wealth (Ridgeway, 20II). These gendered expectations on the roles of different groups of people become norms, which also affect the access that different groups of people have to resources. Showing the inequalities in livelihood opportunities between people with similar cultural backgrounds, Valdez (2016: I6I9) argues, "different family members within an ethnic household may experience unequal opportunities because multiple power relations and dimensions of identity, such as those rooted in social class and gender, shape family member's access to family resources differently". While it is the case that people's agencies on the access to RBR are affected by socially constructed practices embedded in cultures and norms, intersectional theory is applied in this study to explore whether informal social relation factors lead to more disadvantage/ privilege in access to RBR to some people compared to others. 


\section{Description of the study area}

The study is based on data gathered in three villages of the Mofu ward, situated along the estuaries of the Kilombero River in the Kilombero district, which is located in the eastern part of Tanzania. While the villages of Ihenga, Mofu and Ikwambi have some similarities - for example, they are all located in remote areas of the district and seasonal agriculture is their major livelihood strategy - they simultaneously differ in their cultural backgrounds. People in Ikwambi village are native dwellers ${ }^{4}$ of Kilombero, who depend on seasonal agriculture and fishing for their livelihood, i.e. it is a kind of a homogeneous community. People in Ikwambi practice seasonal farming and fishing as the major livelihood activity. Mofu village hosts the ward's head office, which makes it attractive to people from different cultural groups. In addition, some of the ward's service delivery facilities such as the health centre and secondary school are located in Mofu village. Finally, Ihenga was initially a hamlet of Mofu, but it later became a separate village. It was established by agro-pastoralist migrants, predominantly of Sukuma descent, who bought/ applied for the land from village governments upon their arrival. These migrants tend to live in their own areas, separate from native dwellers. Despite its nature of homogeneous, agro-pastoralist community, Ihenga village now receives migrants from other communities due to the rapid development of its infrastructure. It is the only village in the ward with access to electricity. Furthermore, Ihenga is the only village in the Mofu ward where irrigation activities are conducted.

\section{Methodology}

\subsection{Data and Data Sources}

The major method of data collection is the pre-tested survey questionnaire. The survey was conducted among households living in the selected villages. Before the survey, preliminary study visits were organised to get prior information on RBR and activities that make use of RBR. Interviews were conducted with government officials responsible for the governance of river basins and their resources. At village level, informal discussions took place with leaders of the different groups of resource users. The data from the exploratory field visits were also used to confirm some of the explanatory variables that were used during the survey. Our survey, which took place in March 20r6, covers 203 respondents aged 8 and above who carry out different socio-economic activities along Kilombero River. These 203 respondents were surveyed from a total number of 83 households. The following formula was used to select the households (see also Kothari 2004; Ekise et al. 2013).

$$
n=\frac{Z^{2} p q N}{e^{2}(N-1)+Z^{2} p q}
$$


Where $\mathfrak{n}$ is the sample size (i.e. the number of households to be included in the sample); $\mathrm{N}$ is the population size (i.e. total number of households in all three surveyed villages), with $\mathrm{N}=\mathrm{I} 680$ in our study. $\mathrm{p}$ is the probability that each of the member of the population has an equal chance of being included in the sample; in this study, $p=$ is $0.5^{5}$; $q=I-p ; Z$ is the abscissa for confidence level, with the chosen confidence level of $95 \%, Z=$ I.96; e is the random error, which is considered ro\% for this study. The formula gives us the sample size $(\mathfrak{n})$ of $9 \mathrm{I}$ households. These $9 \mathrm{I}$ households were proportionally sampled from the three villages, depending on the size of the population of each village. The following formula is used to derive the sample size that was drawn from each village.

$$
n(\text { village })=\frac{N(\text { village }) * N}{N}
$$

The population size of Ihenga, Ikwambi and Mofu villages, N(village) were 555, 385 and 740 respectively. The formula above gives the village sample size $n$ (village) of 30 households in Ihenga, 2I in Ikwambi and 40 in Mofu. The response rate was 91\%, whereby a total number of 83 households ( 33 household in Mofu, 32 in Ihenga and I9 in Ikwambi villages) were reached. At the village level, simple random sampling was used to select households to be included in the survey.

After the survey, focus group discussions (FGD) were conducted to supplement survey findings. In each surveyed village, four groups of IO-I5 people were formed from I5 surveyed households. The heads of households/couples were put into different groups from the other members of households. Furthermore, each group was formed by people of the same sex to capture gender differences in responses. Variations in ages, education levels of respondents and differences in livelihood activities were considered when forming the groups to improve the external validity of the findings. Both concepts of rights to use resources and decision making regarding the use of goods that were produced from those resources were discussed.

\subsection{Models and the variables}

A multivariate probit regression is used to estimate rights to use RBR and a generalized ordered logit model (GOLOGIT) is used to estimate the ability to benefit from the uses of $\mathrm{RBR}^{6}$. The next section outlines the specification of the two models. 
Respondents were asked to choose (from the list of RBR) the types of RBR that their households possess/have rights to use, and thereafter to choose the kind of RBR that an individual respondent normally uses (depends on) to pursue livelihood activities. RBR that are used by people in the Kilombero district include water for irrigation, irrigable land, pasture and fishery. As in other places in Tanzania, access to irrigated water in Kilombero is linked with the household's possession/renting of irrigated land along the river (Kramm \& Wirkus, 20I0). Access to pasture is also linked with access to traditional pastoralism i.e. access to pasture reflects people who have rights to keep cattle and thus make use of the household's pasture. Access to fishery is linked with the right that household members have to conduct fishing activities. Thus, three variables, i.e. an individual's right to use irrigated land (ILNUR_D), an individual's right to use a pasture (PSTUR_D) and an individual's right to fishing (FSHUR_D) are used to capture the concept of right to use RBR. All three variables are dummies, taking values $\mathrm{I}$ if the right is possessed and o if otherwise. Since our model has a series of binary dependent variables, a multivariate probit regression (MVPM) was used to estimate the system of equations (Cappellari \& Jenkins, 2003) 7 . The equation is modelled as

$$
Y^{\kappa}{ }_{i t}=X_{i t}^{*} \beta^{*}{ }_{\text {it }}+\varepsilon^{*}{ }_{\text {it' }} \quad Y_{\text {it }}=\text { I if } Y^{\kappa}{ }_{\text {it }}>0,0 \text { otherwise } \quad i=I \ldots n ; t=I \ldots T
$$

Where:

$\mathrm{Y}_{\mathrm{it}}=$ individual access to a certain livelihood resource

$X_{\text {it }}=$ Vector of explanatory variables

$\beta_{\mathrm{it}}=$ Vector of parameters to be estimated

$\varepsilon_{\text {it }}=$ error term

An independent variable FEMALE is used to capture the impact of gender on access to RBR. FEMALE is a dummy variable, which takes the value of $\mathrm{I}$ if a person is female and o if a male. A negative relationship is expected between FEMALE and ILNUR_D, FSHUR_D and PSTUR_D. A variable that shows age differences (AGEE) is added to capture if there are differences in access to RBR that are associated with age. As old people are assumed to have accumulated more resources than the young ones, increase in AGEE by one year is expected to be positively related with ILNUR_D, FSHUR_D and PSTUR_D. Furthermore, a variable NAT_D is added to capture the differences in impact between the native dwellers and non-native dwellers. NAT_D is expected to be positively related with FSHUR_D because fishing is a traditional activity of native dwellers of Kilombero. A negative relationship is expected between NAT_D and ILNUR_D and between NAT_D and PSTUR_D.

To study the ability to benefit from the use of RBR, a variable FRDOM is used. FRDOM captures a respondent's answer on a statement as to whether he/she is able (free) to use what he/she has produced to achieve personal goals in life. FRDOM is a Likert scale, taking 
the values from $\mathrm{I}$ to 3 , whereby $\mathrm{I}=$ disagree (DG), 2 = neither disagree nor agree (NAD) and $3=$ agree (AG). In this case, since the outcomes of the responses are ordered in a particular manner, but the distances between the answers is not known, an ordered logit model (OLOGIT)/ proportional odds model was used to estimate the equations (Williams, 20I6).

$$
W^{\star}{ }_{i}=Z_{i}^{\star} \delta_{i}^{\star}+v_{i}^{\star} \quad e \sim \operatorname{Normal}(0, I)
$$

$W^{*}{ }_{i j}$ is a latent dependent variable that shows the choice an individual i makes among $\mathrm{j}$ alternatives, which are ordered in a particular manner. The observed choices are based on one's feelings towards freedom and are ranked in an ordered manner. $Z_{i}^{*}$ is a vector of explanatory variables related to informal social relations and individual access to RBR, $v^{*}{ }_{i}$ is an error term. The model does not have an intercept; instead, it has 2 (i.e. j-I $)^{8}$ cut points (thresholds) that the choices can fall. If we let $\mu_{\mathrm{I}}$ and $\mu_{2}$ be the thresholds, with $\mu_{1}<$ $\mu_{2}$, the observed choice $W_{\mathrm{i}}$ is defined as ${ }^{9}$

$$
W_{i}=\left\{\begin{array}{c}
D G \text { if } Z_{i} \delta_{i}<\mu_{1} \\
N A D \text { if } \mu_{1}<Z_{i} \delta_{i}<\mu_{2} \\
A G \text { if } Z_{i} \delta_{i}>\mu_{1}
\end{array}\right.
$$

To assess the impact of location and cultural norms on FRDOM, three different analyses were done by running three models. The first model includes the informal social relations' variables and rights to use RBR. The model predicts the negative relationship between FEMALE and FRDOM. Increase in AGEE by one year is expected to be positively related with FRDOM. The impacts of ILNUR_D, FSHUR_D PSTUR_D and NAT_D on FRDOM cannot be predicted with certainty, as there is no theoretical evidence to support the arguments. Thus, we expect either positive or negative relationships between access to livelihood resources and FRDOM. To see if there are differences that can be associated to locational and cultural factors, the second model adds to the first model the dummy variables that control for village differences and native dweller (NAT_D) differences. To explore whether gender differences are manifested across locations and cultural groups, the third model adds to the second one, interaction variables between FEMALE and the variables that show locational/ native dwellers differences and rights to use RBR.

8 In our case, the dependent variable has 3 choices, thus $j=3$.

9 Post-tests were conducted to determine whether the assumption of parallel regression/ proportional odds are not violated. Results show the violation of the assumption, thus analysis and interpretations of results were based on a more generalized model of ordinary outcomes, namely generalized ordered logit (GOLOGIT) model (Long \& Freese, 2003; Williams, 2006). 


\section{Results}

\subsection{Rights to use River Basin Resources}

Table I presents the results from the multivariate probit model. As predicted by the model, women are less likely to have rights to use RBR compared to men. Results show that women in Kilombero are less likely to have rights to fishing compared to men. Regarding rights to fishing, as expected by the model, the coefficient of the variable NAT_D shows that native dwellers of the Kilombero district are more likely to have access to fishing than the non-native dwellers. These findings probably reflect the fact that non-native dwellers who are agro-pastoralists, do not practice fishing as a livelihood activity. It was revealed during FGD that in Ndamba's norms, fishing is a male activity. Cultural norms prohibit women from practicing fishing as a livelihood activity. Because of norms, women are not even allowed to visit fishing areas/ camps (mtoni) and thus most of them have never been to the fishing areas. They can only catch fish for food in the streams/ ponds close to their houses during the rainy seasons. An old Ndamba's woman in Mofu village said "Us women from Ndamba's cultural group do not know anything about the rivers. We do not even know the places that the fishing camps are located as we have never been there. We only know the road that takes people to the camps but our traditions do not allow us to go there. For example we heard that in the Kibasila dam, there are frogs that breastfeed, however we have never been there to experience that incidence, ourselves". Women are considered too weak to fight crocodiles that are found in the big rivers. A male respondent in Signal village added, "It is too risky for women to do fishing because most of the fishing activities take place during night time". While there are women from town areas who visit the fishing camps to conduct business such as selling fruit (ripe bananas) and warm cooked meals, married local women complained about this behaviour. Expressing her dissatisfaction, a woman in Ikwambi_M village said, “Town's women go to fishing camps not only for business purposes but also to seduce our men. Once our spouses (husbands) meet these women, they never come back to the villages with money for the households". Some men mentioned that it is a curse for women to visit fishing camps. There is a belief in Ndamba's community that the presence of women in fishing areas results in misfortunes like the disappearance of fish. They believe that, nowadays, there is not enough fish in the rivers because of the presence of women at the fishing camps. 


\begin{tabular}{l|l|l|l|l|l}
\hline \multicolumn{2}{c|}{ PSTUR_D } & \multicolumn{3}{c}{ FSHUR_D } \\
\hline \multicolumn{2}{c|}{ Coef. $\mathbf{P}>\mathbf{z}$} & \multicolumn{3}{c}{ Coef. $\mathbf{P}>\mathbf{z}$} \\
\hline \multicolumn{3}{c|}{ Informal Social relations } & \multicolumn{3}{c}{ Informal Social relations } \\
\hline FEMALE & $-\mathrm{I} .095$ & $0.024^{\star}$ & FEMALE & -1.089 & $0.006^{\star \star}$ \\
\hline \multicolumn{2}{l}{} & Native & Dweller & \\
\cline { 3 - 5 } & NAT_D & 0.780 & $0.000^{\star \star}$ \\
\hline
\end{tabular}

** Significant at $1 \%$ level; * Significant at $5 \%$ level. Source: Stata output.

Table 1: Rights to use RBR: overview of findings.

Findings from the regression analysis summarised on the left hand side of Table I highlight that women are also less likely to have rights to use pasture. These results were also confirmed during the FGD. In pastoralist communities, all cattle belong to men, mostly to the heads of households. Sukuma's traditions do not allow women to hold assets such as cattle and land, and for that reason Sukuma women do not use their earnings to buy cattle, as they automatically become property of the men. As to married women, they do not use their money to buy cattle, as they fear that men will either sell them or use them to pay the bride price to acquire more wives. Young unmarried women mentioned that even if they buy a goat or a cow, they could never be allowed to take them to their husbands once they get married. A young woman said, "If I use my money to buy a goat, the goat will automatically belong to my father. I will never be allowed to take cattle with me to my husband on the day that I get married. Everybody expects a girl to own cows or goats through her husband".

\subsection{Ability to benefit from resources (FRDOM)}

Table 2 presents the results on FRDOM. As predicted by the model, results show that women appear not to have the freedom to make decisions on the use of the goods they produce. Interestingly, model 3 , which includes interaction variables, reveal that the impact of gender on FRDOM differs according to ages and cultural norms. While results from all three models show that old people are supportive of a statement of FRDOM, results on NATAGE_FEM, the interaction between NAT_D, AGEE and FEMALE, show that old women who are also native dwellers are more likely to agree with the statement of FRDOM compared to the women who are non-native dwellers. These results were also confirmed in FGDs. Apart from women in the native Ndamba community, a majority of women admit either involving the husbands or making decisions jointly with their husband. Women in the Sukuma community must involve their husbands whenever they want to sell their crops, even crops that were produced by the women themselves. In some households, failure to involve the husband might even result in a divorce. After selling the crops, some men tend to control their wives' expenditures. Young unmarried Sukuma women cannot use the household's produced goods, even if they were involved in producing the crops, and they depend on their mothers to provide them with basic needs. As to the young boys, both married and unmarried, they depend on their parents' 
decisions if they live in their parents' houses. In Sukuma traditions, young men do not leave their parents' houses immediately after getting married but only when they have their own areas to cultivate. Thus at pastoralist households, people cultivate together and the male head of household is the one who make decisions on behalf of everybody.

On the other hand, women who are native dwellers of Kilombero have more decision-making power compared to other cultural groups. The group of female spouses who are native dwellers boasted that men could not control the uses of the goods that they themselves produced. In some households of Ndamba's communities, women cultivate household plots, but at the same time they cultivate their own personal fields. These women are free to use the crops of their private farms without interference from men. For the goods that were produced collectively with their spouse, they make decisions together. In some households, the couples distribute the goods evenly between husband and wife: thereafter, everyone decides how to use his/ her share of goods. However, the story is different for the young married women in the Ndamba community. In the early stages of the marriage, young women must ask the husband for permission to cultivate their own fields. A young Ndamba married woman said, "even though we do farming activities together, after harvesting, the husband (head of household) becomes the owner of the crops. He is the one who decides whether to sell or not". A husband may allow his wife to have a separate field to grow vegetables, but not paddy rice. Nevertheless, as these marriages grow older, the women generally become more independent and start to cultivate and sell their own paddy rice. For the young unmarried women and men, the norms of native dwellers of Kilombero do not deny young women and men the rights to cultivate their own farms or to sell the goods they have produced. However, they are supposed to leave some of the crops for the household's consumption.

Results related to village differences show that, while people in Ihenga are more likely to have the freedom to make decisions on the use of the goods they produce, people in Ikwambi village are less likely to have the freedom compared to people in Mofu. Further results on the interaction between FEMALE and villages show that women in Ihenga and Ikwambi_M villages are more supportive of the statement of FRDOM compared to women in Mofu village. FGD results concur with the findings by showing that cultural norms are important determinant for the way people live in their societies. Ihenga and Ikwambi_M are both rather homogeneous villages, though they differ in cultural backgrounds. Ikwambi_M is a typical fishing (Ndamba) community, where most of people who reside there are native dwellers of Kilombero. During FGD, women, who are native dwellers, appear to have more decision making power compared to women from other cultural groups. As regards Ihenga, FGD and survey findings differ. During FGD, some participants in Ihenga village insisted that the decisions are taken jointly, while other participants challenged them by saying that in Sukuma traditions only the husband (the head of household) takes decisions on whether to consume or to sell. However, it was also observed during FGD that not all women seem to comply with the norms, as some women reported that they silently resist these norms. One of the participants said, "When I want to buy my own things such as new dresses, I need to seek advice and sometimes permission from 
my husband". She continued by saying that "as a woman, sometimes you have to use your brain to be able to buy new things. For example, I may buy a new dress and give it to a friend to wear it for the first time. Then the friend return the dress to me after washing it so it does not look new to the husband. By doing that, my husband may not complain that I have squandered the money by buying unnecessary stuffs". Such statements somehow imply that women find their own ways to benefit, silently, without being accused of violating the norms. Young unmarried Sukuma women cannot use the household's produced goods, even if they were involved in producing the crops, and they depend on their mother to provide them with basic needs. As to the young boys, both married and unmarried, they depend on their parent's decisions if they live in their parents' houses. In Sukuma traditions, young men do not leave their parent's houses immediately after getting married but only when they have their own areas to cultivate. Thus in pastoralist households, people cultivate together and the male head of the household is the one who makes decisions on behalf of everybody. Finally, Mofu village hosts people from different cultural backgrounds who have migrated to look for farming land. Thus, due to the multicultural nature of the villages, there might be different results regarding FRDOM.

\begin{tabular}{|c|c|c|c|c|c|c|c|c|c|}
\hline & \multicolumn{3}{|c|}{ Model I } & \multicolumn{3}{|c|}{ Model 2} & \multicolumn{3}{|c|}{ Model $_{3}$} \\
\hline & \multicolumn{2}{|c|}{ Coefficients } & \multirow[t]{2}{*}{$\mathrm{P}^{\star}$} & \multicolumn{2}{|c|}{ Coefficients } & \multirow[t]{2}{*}{$\mathrm{P}^{\star}$} & \multicolumn{2}{|c|}{ Coefficients } & \multirow[t]{2}{*}{$\mathrm{P}$} \\
\hline & disagree & $\begin{array}{l}\text { agreel } \\
\text { disagree }\end{array}$ & & disagree & \begin{tabular}{|l} 
agree/ \\
disagree
\end{tabular} & & disagree & \begin{tabular}{|l|} 
disagreel \\
agree
\end{tabular} & \\
\hline \multicolumn{10}{|c|}{ Informal Social relations } \\
\hline AGEE & 0,209 & 0,046 & $0.001^{\star \star}$ & 0,247 & 0,035 & $0.000^{\star \star}$ & $0,48 \mathrm{I}$ & 0,052 & 0.000 \\
\hline FEMALE & 0,615 & $-I, 545$ & $0.000^{\star \star}$ & o,6I9 & $-1,609$ & $0.000^{\star \star}$ & $\mathrm{I}, 949$ & $-2,885$ & 0.000 \\
\hline \multicolumn{10}{|c|}{ RBR } \\
\hline ILNUR_D & $-0,55$ & 0,26 & $0.016^{\star \star}$ & $-0,496$ & 0,613 & $0.003^{\star \star}$ & $-\mathrm{I}, 066$ & 2,501 & $0.000^{\star \star}$ \\
\hline FSHUR_D & $\mathrm{I}, \mathrm{I7}$ & $-1,08$ & $0.024^{\star}$ & 1,522 & $-\mathrm{I}, 284$ & $0.005^{\star}$ & & & \\
\hline PSTUR_D & $-1,73$ & $\mathrm{I}, 98$ & $0.000^{\star \star}$ & $-\mathrm{I}, 489$ & I,606 & $0.000^{\star \star}$ & & & \\
\hline \multicolumn{10}{|c|}{ Age interaction } \\
\hline NATAGE & & & & & & & 0,064 & $-0,024$ & 0.003 \\
\hline NATAGE_FEM & & & & & & & $-0,118$ & 0,024 & $0.000^{\star \star}$ \\
\hline \multicolumn{10}{|c|}{ Village Differences } \\
\hline Ihenga & & & & 0,160 & o, I6o & 0.7480 & $-23,783$ & $2,99 \mathrm{I}$ & $0.000^{\star \star}$ \\
\hline Ikwambi_M & & & & $-0,417$ & $-0,417$ & 0.3677 & $-0,093$ & $-3,430$ & $0.014^{\star}$ \\
\hline \multicolumn{10}{|c|}{ Village interaction } \\
\hline \multicolumn{10}{|c|}{ Female \& Village } \\
\hline FM_IHE & & & & & & & 2,928 & 2,928 & $0.005^{\star \star}$ \\
\hline FM_IKWM & & & & & & & $-1,799$ & 2,289 & $0.008^{\star \star}$ \\
\hline \multicolumn{10}{|c|}{ RBR interaction } \\
\hline \multicolumn{10}{|l|}{ RBR \& Female } \\
\hline ILN_FEM & & & & & & & 8,887 & I,003 & $0.008^{\star}$ \\
\hline ILNAGE_FEM & & & & & & & $-0,160$ & 0,002 & 0.0217 \\
\hline
\end{tabular}

** Significant at $1 \%$ level; * Significant at $5 \%$ level. Source: Stata output/Own estimation.

Table 2: Ability to benefit from the use of RBR: Overview of findings. 
Focusing on the variables that measure right to use RBR, findings in Table 2 show that rights do indeed affect the ability to benefit from resources. In all three models, people with right to irrigated land are more likely to support the statement of FRDOM. Results on (ILN_FEM), interaction between ILNUR and FEMALE, show that women with rights to use irrigated land are more supportive of the statement of FRDOM. When the age variable is added to the interaction, results show that old women with rights to irrigated land are more likely to have freedom to make decisions on the goods they produce as compared to women without the rights to irrigated land.

Results on the impact of FISHUR_D on FRDOM (model I and 2) show that people who have rights to fishing (versus people with no rights) are less likely to agree that they are free to make decisions on the use of the goods they produce. While fishing is a traditional men's activity according to Ndamba's norms, it was admitted during the FGD that men in fishing communities do make decisions together with their spouses. Men spend most of their time in fishing camps; sometimes they stay there for months. Thus, they automatically leave all household issues to be dealt with by the women. Men in the fishing communities said themselves that although men are considered household heads, women are empowered to make decisions. One respondent added that "our women are stubborn: we cannot do a thing without involving them". Furthermore, in fishing communities, some married men do not practice agriculture activities at all. In such a situation, a wife (mother) becomes the main custodian of food, while the husband (father) is expected to bring home income from fishing. The wife is the one who keeps all the stock of food: she is considered as the family's treasurer and a storekeeper. Thus, the woman is free to use/ sell agricultural products without interference from the husband. The wife is the one who makes sure that there is enough food for the family, i.e. not all food is sold. One of the men said, "Since we were born, men were socialized to fish and women were socialized to take care of the families and to conduct agriculture activities. We men spend many days at the fishing areas, thus so many decisions regarding the households are left in the hands of wives (women)". While these women seem to benefit from the use of resources (even without having access to the fishing activity itself, see findings right hand side Table I), some of them say that their control over the income from fishing is limited because they are not sure of the amounts men earn from the activity. Women complain that men's income from fishing is mostly spent at the fishing camps with businesswomen from town areas who visit the fishing camps. Thus, only a small amount is left for household consumption. One of the woman said that "Today, you are lucky to find our men in the village because it is raining, otherwise you wouldn't find them here. They spend many days at fishing camps but they bring very little income home for household uses. Sometimes they even do not bring money home, they just send some few fishes for food purpose. Since we are not allowed to go to fishing camps, we cannot control the money they earn and their expenditures. Sometimes we think a lot of money is spent with the women from town areas who visit the fishing camps. We always see the town women, who are carried on the motorcycles, passing our village to the fishing camps".

Results for individual's right to use pasture (PSTUR_D) are statistically significant in model I and model 2. Both models show that people with rights to use pasture are 
more supportive of the statement of FRDOM. The results are insignificant for the model that includes interaction variables. Results from FGD confirm these results by showing that men in pastoralist communities are the ones who own cattle and land and thus the ones with the right to use pasture. Furthermore, the traditions of pastoralist communities also give men the right to make decisions on the use of goods that are produced in the households.

\section{Discussion}

This paper has used empirical data to study gender and access to RBR among native and non-native dwellers living along the Kilombero River in Tanzania. The study found that, the practical rights on the use of RBR are highly gendered, which also results in a gendered distribution of labour, both among native and non-native dwellers of Kilombero. The commonality in findings between the native and non-native dwellers of Kilombero is that the norms from both cultural groups deny women access to RBR, especially when access to RBR leads to income-generating activities such as fishing and traditional pastoralism ${ }^{\text {Io }}$. These activities are traditionally termed as men's jobs. This implies that women's livelihoods in Ndamba and Sukuma communities might be affected, not necessarily because resources are unavailable, but due to cultural norms that restrict women from using certain RBR (see also Leach et al., I999). These findings are in line with the studies by Kavishe, (I99I), Omari (I989) and Skoog (I993), which have also shown the gender distribution in activities conducted by people in rural areas of Tanzania. In our study, women seem to have access to RBR, that are used in the production of crops. This means that while men are engaged in multiple activities that use RBR, women are responsible for the production of goods that do not reach the markets i.e. goods that are, directly, consumed by the households.

In addition to the negative impact of gender on the practical rights to use RBR, the findings also show the negative impact of gender on the ability to benefit from the use of resources. Thus, these findings confirm the first and second hypotheses. However, the gender impact on the ability to benefit from the use of resources differs between different groups of women i.e. between old and young women and between native and non-native dwellers. Among the native dwellers, old women (married and non-married) have the ability to benefit from the use of RBR, while young married women do not have that ability. In line with intersectionality theories, the findings imply that women cannot be considered a homogeneous group not even in a single community. Furthermore, norms that allow native women of Kilombero to own and cultivate their own land separately from the household plots give them some sort of power to make decisions on the use of the goods they produce, compared to women in pastoralist communities. These findings are in line with the study by Lyimo-Macha \& Mdoe, (2002), which show that in areas of the Morogoro Rural district where women inherit land, women have more decision making

Io The importance of cattle to Sukuma was also explained in the study by Drangert (1993) who said that purchasing of cattle is the most preferable investment in Sukuma community because cattle reproduce themselves and they can easily be converted to cash. 
power as regards the use of land compared to women in other cultural groups. Because of norms that deny ownership of land, women in pastoralist communities depend on men for production and for consumption decisions. From these findings, the conclusion can be drawn that women cannot be conceived of as a homogeneous group; they differ between and within cultural groups.

The impact of the rights to use RBR on the ability to benefit from the use of RBR is also gendered yet differs between pastoralist and fishing communities. On the one hand, findings on the people's rights to use irrigated land and rights to use pasture confirm the third hypothesis that the rights that men and women have on the use RBR translates unequivocally into their ability to benefit from the use of RBR. On the other hand, the findings that people with the rights to fishing are not able to benefit from the use of RBR reject the third hypothesis. It is interesting to note that the same norms that give men the advantage of practising fishing activity, give them less opportunity to make decisions on the use of goods produced from within the household.

In addition, while it was predicted by our hypothesis that women would be less likely to benefit from the use of RBR due to norms that deny them access to important resources, this hypothesis was not confirmed amongst the fishing communities of Kilombero. Both quantitative and qualitative results show that women in a fishing community are more likely to benefit from the use of RBR. Although the norms deny them the right to fish, women in fishing communities seem to accrue benefits from fishing activities by being the major custodian of their households' food reserves and income. From these findings, another conclusion can be drawn that both men and women are heterogeneous groups in the communities examined. because The fact that women are denied the right to use important livelihood resources does not necessarily mean they are not able to benefit from the use of those resources. Furthermore, our qualitative data also suggest that women have been able to find ways to benefit, sometimes by silently resisting the norms. This evidence is not unique to the Tanzanian context. Abdullah \& Zeidenstein (Ig82) earlier reported similar evidence for South Asia where women, silently, resist the norms that restrict their access to important resources by for example letting their neighbours raise cattle for them so that husbands do not know that they possess those kinds of goods.

\section{Conclusion and policy implications}

Rights based on physical ownership and rights to use resources and structural-based mechanisms in terms of access to labour and other means of production have received more attention in empirical studies of access to resources than studies on the ability to benefit from the use of resources. This study contributes to the literature of access to resources by showing that it is important to distinguish between rights to use resources and the ability to benefit from resources.

Our study shows that gender differences embedded in norms affect rights to use RBR and the ability to benefit from the use of resources. In general, women are found to have no advantages in terms of the rights to use RBR and the benefits from the use of resources, though the latter does not apply to all women. The study recommends the policies which 
are targeted to improve women's livelihoods in rural areas should take into account not only the types of activities that women (and men) engage in, but also whether or not they are able to use the goods they produce to improve their livelihood situations. While people with rights to use RBR may seem to be in an advantageous position because they are able to engage in economic activities, their livelihoods may be disadvantaged as much as those without the rights, if they are not allowed to use the goods they produce to achieve their goals in life.

The study shows that access in terms of the ability to benefit from the use of resources differs between pastoralist and fishing communities, and also within the single community. These findings show the importance of further distinguishing between groups of respondents; women and men are heterogeneous groups that differ according to age and cultural background. Thus, we emphasizes that future studies apply intersectionality approaches when studying access to resources. Subsequently, we recommend the policies that aim to improve women's (and men's) livelihoods should consider not only differences between the communities but also within the communities.

Findings reveal that old women in the fishing community under study are able to benefit from the use of RBR despite their lack of fishing rights. As a result, one may argue that the village women have more power to access resources because they live in their own local clan. Agro pastoralist women might have lost their power after migrating to new areas with different practices of cultural norms. These findings deserve comparative study of livelihoods of agro-pastoralists who stay in their own local clan and those who have migrated to other areas. Furthermore, since the study has not established the reasons for some of the pastoralist women's actions of, silently, resisting the norms, future researchers can conduct in-depth studies of these covert behaviours to come up with more solid recommendations on inequalities in access to resources.

Power relations between men and women are the result of practices that have been inherited from previous generations, though they change as society and its priorities change. The changes in these practices may be brought about by factors such as changes in climate, socio-economic conditions, population, technology etc., (Leach et al., I999). Because of these changes, individuals have found themselves changing their strategies and adopting new ways of livings which also result in changes in their norms and rules. Thus, the study recommends future research to pay attention to the process or social trajectory through which power relations between men and men change over time.

This paper has studied quantitatively the intersections of informal social relations variables. Other studies may consider studying qualitatively the manner in which these inequalities in access to RBR occur. This can be done by, for example, attending to the voices of people who are locked into the intersections of those social categories. The behaviour that may be perceived by outsiders as a discriminative norm, may not necessarily be perceived as such by the community, even by those who seemed to be affected by those conducts. 


\section{Acknowledgement}

This paper was written based on the findings of ongoing PhD research on an analysis of household development strategies and their linkage to RBR Degradation in Tanzania. The $\mathrm{PhD}$ is one of the components of the project on promotion of good governance through integrated community-based activities in Tanzania sponsored by the Belgian government through the VLIR-UOS under the Governance and Entrepreneurship through Education, Research, Access and Technology for Tanzania (Gre@t) programme. Special thanks to my promoters Prof. Dr. Nathalie Holvoet (IOB, University of Antwerp), Dr. Romanus Dimoso (Mzumbe University) and the reviewer of the article. All remaining errors are the author's sole responsibility.

\section{Disclosure statement}

The author's father belongs to the Sukuma community while her mother is from a different cultural background.

\section{References}

Agarwal, B. (1997). "Bargaining" and Gender Relations: Within and Beyond the Household. Feminist Economics, 3(I), I-5I.

Abdullah, T. \& Zeidenstein S. A. (1982). Village Women of Bangladesh: Prospects for Change. In Agarwal, B. (1997). "Bargaining" and Gender Relations: Within and Beyond the Household. Feminist Economics, 3(I), I-5I.

Becker, G. S. (1965). A Theory of the Allocation of Time. The economic journal, 493-517.

Best, R. K., Edelman, L. B., Krieger, L. H., \& Eliason, S. R. (20II). Multiple Disadvantages: An Empirical Test of Intersectionality Theory in EEO Litigation. Law \& Society Review, 45(4), 99I-IO25. doi:IO.IIII/j.I540$5893.2011 .00463 \cdot x$

Cappellari, L., \& Jenkins, S. P. (2003). Multivariate probit regression using simulated maximum likelihood. The Stata Journal, 3(3), 278-294.

Cleaver, F. (200I). Institutional bricolage, conflict and cooperation in Usangu, Tanzania. IDS Bulletin, 32(4), 26-35.

Cleaver, F., \& Toner, A. (2006). The evolution of community water governance in Uchira, Tanzania: The implications for equality of access, sustainability and effectiveness. Paper presented at the Natural Resources Forum.

De Haan, L., \& Zoomers, A. (2005). Exploring the frontier of livelihoods research. Development and change, $36(\mathrm{I}), 27-47$.

Drangert, J.-O. (1993). Who cares about water? Study of household water development in Sukumaland, Tanzania. Department of Theme Research, Water and Environmental Studies, Linköping University.

Ekise, E.I., Nahayo, A., Mirukiro, J., Nsengiyumva, B. (2013), "Analysis of the impact of agricultural input subsidies voucher programme on the livelihoods of small scale maize producers in Kirehe district, eastern Rwanda", New York Science Journal, Vol. 6, No 9, pp.32-44.

Ellis, F. (2000). Rural Livelihoods and Diversity in Developing Countries. Oxford: Oxford University Press.

Haddad, L. J., Hoddinott, J., \& Alderman, H. (1997). Intrahousehold resource allocation in developing countries. Johns Hopkins University Press.

Hall, K., Cleaver, F., Franks, T., \& Maganga, F. (20I4). Capturing Critical Institutionalism: A Synthesis of Key Themes and Debates. European Journal of Development Research, 26, 7I-86.

Hill Collins, P. (2000). Black feminist thought: knowledge, consciousness, and the politics of empowerment, 2nd ed. Routledge, New York and London. 
Jones, N., Harper, C., Watson, C., Espey, J., Wadugodapitiya, D., Page, E., Clench, B. (2010). Stemming Girls' Chronic Poverty: Catalysing Development Change by Building Just Social Institutions.

Kavishe, F. P. (I99I). Food access and nutrition policy/programme linkages in mainland Tanzania: Department of Agricultural Economics and Extension (DAEE), University of Zimbabwe (UZ).

Kothari, C.R., (2004). Quantitative Techniques, New Delhi, Vikas Publishing House Pvt. Ltd., p.64, I978.

Kramm, J., \& Wirkus, L. (20I0). Local Water Governance: Negotiating water access and resolving resource conflicts in Tanzanian irrigation schemes.

Leach, M., Mearns, R., \& Scoones, I. (I999). Environmental entitlements: dynamics and institutions in community-based natural resource management. World Development, 27(2), 225-247.

Leavens, M., \& Anderson, C. (20II). Gender and Agriculture in Tanzania. EPAR Brief (Vol. I34). Seattle, USA: Evans School Policy Analysis and Research, University of Washington.

Long, J. S., \& Freese, J. (2003). Regression models for categorical dependent variables using Stata: Stata Press.

Lyimo-Macha, J., \& Mdoe, N. (2002). Gender and rural poverty in Tanzania: Case of selected villages in Morogoro rural and Kilosa districts. Retrieved from

Mehta, L., Leach, M., \& Scoones, I. (200I). Environmental governance in an uncertain world. IDS Bulletin, 32(4), I-9.

Meinzen-Dick, R (20I4). Property rights and sustainable irrigation: A developing country perspective, Agricultural Water Management I45 (2014) 23-3I.

Meinzen Dick, R. S. and Pradhan R., (2002) "Legal Pluralism and Dynamic Property Rights", CAPRi Working Paper NO. 22

Omari, C. (I989). Rural Women, Informal Sector and Household Economy in Tanzania, Helsinki. World Institute for Development, Economic Research of the United Nations University.

Ribot, J. C., \& Peluso, N. L. (2003). A theory of access. Rural Sociology, 68(2), I53-I8I.

Ridgeway, C., 20Ir. Framed by Gender: How Gender Inequality Persists in the Mod-ern World. Oxford, New York.

Rocheleau, D., Thomas-Slayter, B., \& Wangari, E. (I996). Gender and environment: A feminist political ecology perspective. Feminist political ecology: Global issues and local experiences, 3-26.

Sen, A. (I999). Freedom as development. Oxford University Press, Oxford.

Singh, I., Squire, L., \& Strauss, J. (I986). Agricultural household models: Extensions, applications, and policy. The World Bank.

Skoog, G. E. (I993). Peasant response to price incentives in Tanzania: a theoretical and empirical investigation. (Vol. 9I): Nordic Africa Institute.

Williams, R. (2006). Generalized ordered logit/partial proportional odds models for ordinal dependent variables. Stata Journal, 6(I), 58-82. Retrieved from http://www.stata-journal.com/article.html?article=stoog7

Williams, R. (2016). Understanding and interpreting generalized ordered logit models. The Journal of Mathematical Sociology, 40(I), 7-20. doi:I0.I080/0022250X.20I5.III2384. 